\title{
Entity Statement
}

National Cancer Institute

\section{Source}

National Cancer Institute. Entity Statement. NCI Thesaurus. Code C101134.

A declaration of a relationship between entities, consisting of a subject, predicate and object. 